\title{
Evaluación curricular de la ingeniería en Computación de una universidad mexicana desde la percepción de sus egresados
}

Curricular Assessment of Computer Engineering from a Mexican University from the Perception of its Graduates

Avaliação curricular de Engenharia da Computação de uma universidade mexicana na percepção de seus graduados

Oscar Solis Rodríguez

Universidad de Guadalajara, México oscar.srodriguez@academicos.udg.mx https://orcid.org/0000-0003-3966-8641

María del Consuelo Cortés Velázquez

Universidad de Guadalajara, México maria.cortes@academicos.udg.mx https://orcid.org/0000-0001-5387-7226

Claudia Patricia Figueroa Ypiña Universidad de Guadalajara, México claudia.fypina@academicos.udg.mx https://orcid.org/0000-0002-0305-2688

Aurelio Enrique López Barrón Universidad de Guadalajara, México aurelio.Ibarron@academicos.udg.mx https://orcid.org/0000-0003-4742-5316 

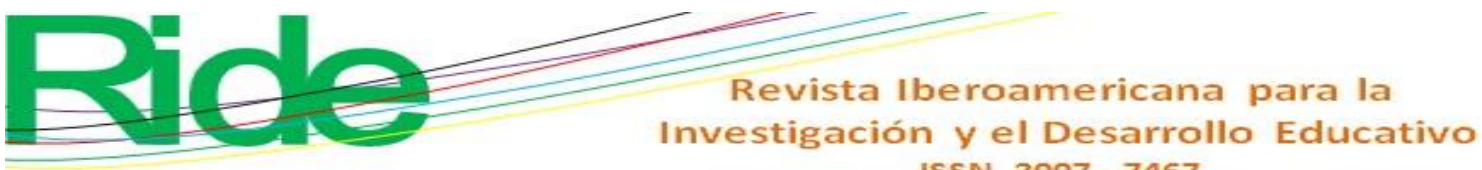

ISSN $2007-7467$

\section{Resumen}

Este trabajo tuvo como finalidad evaluar el currículo de la ingeniería en Computación de una universidad mexicana. Desde la perspectiva de sus egresados, se respondieron planteamientos relacionados con el cumplimiento de los objetivos del currículo, el nivel de satisfacción académica y la identificación de fortalezas y debilidades de la carrera.

La evaluación se llevó a cabo mediante un enfoque mixto. Para ello, se aplicó el modelo CIPP de Stufflebeam y Shinkfield (1987/2011), cuyo nombre responde a las cuatro etapas que lo integran: contexto, entrada, proceso y producto. Debido al propósito de la investigación, la evaluación se centró específicamente en la etapa de producto. La recolección de datos contempló la revisión del documento institucional en donde figuran los objetivos del currículo, la aplicación de dos cuestionarios a 63 egresados y una entrevista a un grupo focal integrado por 13 participantes. En el análisis de datos, a partir del documento institucional, se efectuó un análisis de contenido; a partir de la información obtenida de los cuestionarios, se concretó un análisis estadístico descriptivo y un análisis secuencial de discurso; a partir de los datos recabados en la entrevista con el grupo focal, se hizo también un análisis secuencial de discurso. Acerca de los resultados, se demostró que existe correspondencia entre los logros de la ingeniería en Computación y los objetivos enlistados en el currículo. Además, todos los egresados están siendo preparados con la mayoría de los conocimientos propios de un profesional de esta carrera. Sin embargo, en lo que respecta a las habilidades y destrezas, se está preparando adecuadamente solo a los egresados de la orientación en Software de Sistemas, y no a los de la orientación en Sistemas Digitales, ya que no existe correspondencia entre el perfil de egreso logrado por este y lo establecido en el currículo. Además, se demostró que los egresados están desarrollando actitudes y valores descritos por el currículo. Con relación a la satisfacción académica, los egresados expresaron haber tenido una buena experiencia cursando la carrera. Por último, se identificaron como fortalezas de la carrera el diseño de la malla curricular y las prácticas profesionales, mientras que las debilidades se vincularon con aspectos relacionados con la planta docente, los equipos y la infraestructura.

Palabras clave: calidad en la educación, CIPP, currículo, egresados, evaluación. 


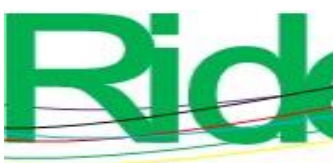

Revista Iberoamericana para la

Investigación y el Desarrollo Educativo

ISSN 2007 - 7467

\section{Abstract}

The purpose of this work was to evaluate the Computer Engineering curriculum of a mexican university. From the perspective of its graduates, proposals related to the fulfillment of the objectives of the curriculum were answered; the level of academic satisfaction; and identifying career strengths and weaknesses.

The evaluation was carried out using a mixed approach. For this, the CIPP model of Stufflebeam and Shinkfield (1987/2011) was applied, which its name responds to the four stages that integrates it: context, input, process and product. It should be noted that, for the purpose of the investigation, the evaluation focused specifically on the product stage. The data collection included the revision of the institutional document containing the objectives of the curriculum; the application of two questionnaires to 63 graduates; and, in addition, an interview with a focus group of 13 participants. In data analysis; based on the institutional document, a content analysis was made; based on the information obtained from the questionnaires, a descriptive statistical analysis and a sequential discourse analysis were made; from the data collected in the interview with the focus group, a sequential discourse analysis was also made.

About the results, the most important finding to note is that it was shown that there is a correspondence between the achievements of Computer Engineering and the objectives listed in the curriculum. In addition, that all graduates are being prepared with most of the knowledge of a professional in this career. However, when it comes to skills and abilities, graduates of Systems Software orientation are being adequately prepared; In the Digital Systems orientation, this does not happen since there is no correspondence between the graduation profile achieved by the graduates and what is established in the curriculum. Furthermore, it was shown that graduates are developing attitudes and values described in the curriculum. Regarding academic satisfaction, the graduates expressed having had a good experience studying the degree. Finally, they were identified; as career strengths, the design of the curricular mesh and professional practices; such as weaknesses, aspects related to the teaching staff and equipment and infrastructure.

Keywords: quality in education, curriculum, CIPP, graduates, evaluation. 

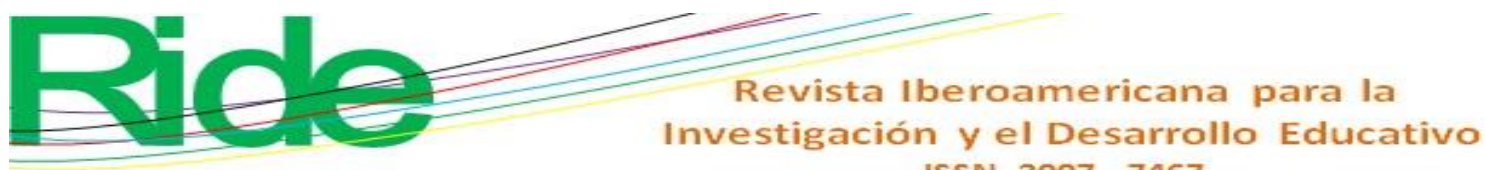

ISSN 2007 - 7467

\section{Resumo}

O objetivo deste trabalho foi avaliar o currículo de Engenharia da Computação de uma universidade mexicana. $\mathrm{Na}$ perspectiva de seus egressos, foram atendidas propostas relacionadas ao cumprimento dos objetivos do currículo, ao nível de satisfação acadêmica e à identificação de pontos fortes e fracos da carreira.

A avaliação foi realizada por meio de uma abordagem mista. Para isso, foi aplicado o modelo CIPP de Stufflebeam e Shinkfield (1987/2011), cujo nome responde às quatro etapas que o compõem: contexto, entrada, processo e produto. Devido ao objetivo da pesquisa, a avaliação se concentrou especificamente na etapa do produto. A coleta de dados incluiu a revisão do documento institucional que contém os objetivos do currículo, a aplicação de dois questionários a 63 egressos e uma entrevista com um grupo focal composto por 13 participantes. Na análise dos dados, com base no documento institucional, foi realizada uma análise de conteúdo; A partir das informações obtidas nos questionários, foi realizada uma análise estatística descritiva e uma análise sequencial do discurso; A partir dos dados coletados na entrevista com o grupo focal, também foi feita uma análise sequencial do discurso.

Em relação aos resultados, evidenciou-se que existe uma correspondência entre as realizações da Engenharia de Computação e os objetivos elencados no currículo. Além disso, todos os egressos estão sendo preparados com a maior parte do conhecimento de um profissional dessa carreira. Porém, no que se refere às competências e habilidades, apenas os graduados da orientação de Software de Sistemas estão sendo adequadamente preparados, e não os da orientação de Sistemas Digitais, uma vez que não há correspondência entre o perfil do graduado alcançados por isso e pelo que está estabelecido no currículo. Além disso, foi demonstrado que os egressos estão desenvolvendo atitudes e valores descritos no currículo. Em relação à satisfação acadêmica, os egressos expressaram ter tido uma boa experiência no curso de graduação. Por fim, o desenho do currículo e as práticas profissionais foram identificados como pontos fortes da carreira, enquanto as fragilidades foram vinculadas a aspectos relacionados ao corpo docente, equipamentos e infraestrutura.

Palavras-chave: qualidade em educação, CIPP, currículo, graduados, avaliação.

Fecha Recepción: Mayo 2020

Fecha Aceptación: Octubre 2020 


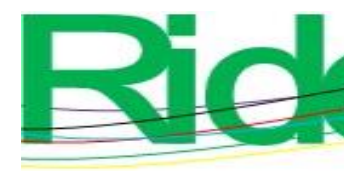

Revista Iberoamericana para la Investigación y el Desarrollo Educativo ISSN 2007 - 7467

\section{Introducción}

La institución de educación pública sede de la presente investigación tiene una historia de más de 200 años y, actualmente, es una de las casas de estudio con mayor prestigio en México (Universidad de Guadalajara, 2018a). Esta universidad se destaca por la formación de recursos humanos de alto nivel y por la producción de conocimientos científicos y tecnológicos, así como por su comunidad académica, una de las más importantes del país (Universidad de Guadalajara, 2018b).Además, está constituida por una red que comprende a seis centros universitarios temáticos, nueve centros universitarios regionales, un sistema de educación virtual y un sistema de educación media superior (Universidad de Guadalajara, 2018c).

Como parte de esta red, en 1994 se fundó un centro universitario regional (en adelante CUR) con el objetivo de generar espacios educativos en el estado de Jalisco, México, para atender la demanda creciente de la ciudad y de otras entidades aledañas, y para fungir como modelo de educación superior que impulsa el desarrollo social y cultural de la región (Centro Universitario de la Costa, 2018a).

Desde sus inicios, el CUR ha tenido un crecimiento progresivo en todos los aspectos. En lo que respecta a la oferta educativa, en 2003 se creó la ingeniería en Computación (en adelante INCO), la cual se incorporó a una oferta que actualmente suma 19 carreras profesionales, 7 maestrías, 3 doctorados y 28 diplomados (Centro Universitario de la Costa, 2018b).

\section{Establecimiento del problema}

Calidad es un término con muchas acepciones. No obstante, para Blanco (1996), cuando se le relaciona con la educación, es posible emplearlo de manera descriptiva o normativa. Este autor describe que la primera se genera cuando "un alumno, un profesor, un centro o un sistema reúnen un cierto número de cualidades o características definitorias", mientras que la segunda se refiere al "grado de excelencia o valor relativo" (p. 21).

Por otro lado, Braslavsky (2006) afirma que la educación puede ser considerada de calidad cuando permite a las personas aprender lo que necesitan en el momento oportuno de sus vidas y de la sociedad. Para lograr lo anterior, la institución de educación pública, en su plan de desarrollo institucional 2014-2030, señala que es de vital trascendencia mejorar los currículos con base en diagnósticos y en las tendencias nacionales e internacionales (Universidad de Guadalajara, 2014). Por su parte, el CUR — en su plan de desarrollo de centro: visión 2030 pone de manifiesto que para elevar sus indicadores es necesario evaluar la pertinencia de los 


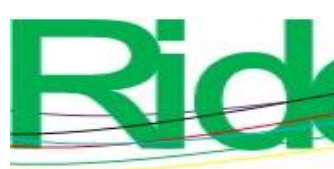

Revista Iberoamericana para la Investigación y el Desarrollo Educativo ISSN $2007-7467$

currículos en relación con las necesidades y tendencias nacionales e internacionales, de acuerdo con el área temática de cada uno de ellos (Centro Universitario de la Costa, 2014).

En consecuencia, para poder determinar si los alumnos están aprendiendo lo necesario en el momento oportuno se requiere de diagnósticos que pongan de manifiesto la pertinencia de cada una de las carreras profesionales ofertadas. Para ello, es indispensable partir de evaluaciones que permitan determinar el estado actual de cada uno estos currículos.

\section{El tema}

El tema de esta investigación es la evaluación curricular. Para este tipo de estudio existen distintos modelos, y a pesar de que no hay un consenso entre los autores sobre su clasificación, se distinguen seis posibles categorías: 1) modelos de resultados, 2) modelos explicativos del proceso, 3), modelos económicos, 4) modelos de actor, 5) modelos de teoría del programa, y 6) modelos sistemáticos (Hansen, 2005).

De acuerdo con Gómez y Mora (2011), cuando la evaluación curricular se vincula con la mejora de la calidad de la educación es un tema de debate, y esto ha ocurrido así desde finales del siglo XX y principios del XXI. No obstante, como ellos lo señalan, más allá de las discrepancias, la evaluación curricular es un método que ha probado ser efectivo y eficaz para conocer fortalezas y áreas de oportunidad.

Antes de continuar con el siguiente punto de este trabajo, es importante mencionar que el currículo "es una tentativa para comunicar los principios y rasgos esenciales de un propósito educativo, de forma tal que permanezca abierto a discusión crítica y pueda ser trasladado efectivamente a la práctica" (Stenhouse, 1984/2010, p. 29). Hasta el siglo XIX, este era conocido como plan de estudios o programa educativo (Valenzuela y Juárez, 2011). Para los fines perseguidos en esta investigación, y en lo sucesivo, se decidió referirse al currículo como tal, salvo algunas excepciones en las que se le denominará plan o programa educativo; esta última disposición en atención a la forma como se aborda en la literatura que se consultó para este trabajo. 


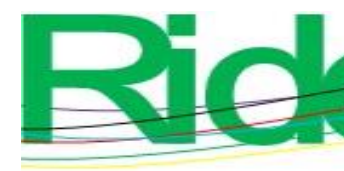

Revista Iberoamericana para la Investigación y el Desarrollo Educativo ISSN $2007-7467$

\section{Problema de investigación}

Según se estipula en el dictamen que avala la creación de la INCO, la carrera fue concebida con el fin de formar profesionales orientados hacia el hardware y el software de los sistemas de cómputo; profesionales con conocimiento básico para ser aplicado en diferentes áreas como la industria, la empresa, la educación y las telecomunicaciones, así como en las múltiples ramas de la ingeniería para concebir las más variadas aplicaciones.

En esta misma documentación también se dan a conocer, además del plan de estudios, los pormenores sobre la creación de la INCO (es decir, justificación, objetivos, perfil de egreso, campo laboral, modalidad, entre otros). Sin embargo, y a pesar de la extensión del dictamen, no se estipula de qué manera se evaluará el propio currículo. Al respecto, Álvarez (2012) advierte que, en la actualidad, el currículo debería estar en un proceso permanente de revisión para tratar de responder a las necesidades cambiantes de una sociedad dinámica.

Desde el año 2000, el CUR ha recurrido a instancias externas para que evalúen y den reconocimiento formal de la calidad de sus programas educativos. En México, este tipo de respaldo lo otorga el Consejo para la Acreditación de la Educación Superior [Copaes] (2018), instancia máxima avalada por el Gobierno federal, a través de la Secretaría de Educación Pública (SEP).

A pesar de que la INCO ya ha sido objeto de evaluaciones de este tipo - o acreditaciones, como se les conoce comúnmente-, autoridades del CUR coinciden en que un proceso de esta índole no proporciona la información cualitativa que permita identificar el nivel de correspondencia entre el currículo de la carrera y sus objetivos, y que tampoco proporciona información capaz de orientar la toma de decisiones con miras a mejorarlo en este sentido (A. E. López, comunicación personal, 7 de octubre, 2017). Se advierte además que las acreditaciones se centran mayormente en alumnos, docentes, directivos y en las instalaciones mismas, quedando rezagados del proceso los egresados. Como resultado, se desconocen tanto el nivel de satisfacción personal que tienen estos últimos con respecto de su formación académica como las fortalezas y áreas de oportunidad de la carrera en el campo laboral (L. R. Salazar, comunicación personal, 8 de octubre, 2017).

Esencialmente, por la situación hasta ahora descrita, quedó de manifiesto que de la INCO se desconoce a) el nivel de correspondencia entre el currículo y sus objetivos, b) el nivel de satisfacción académica de los egresados, y c) las fortalezas y debilidades de la carrera. 


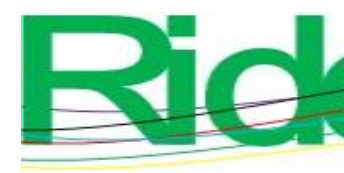

Revista Iberoamericana para la Investigación y el Desarrollo Educativo ISSN $2007-7467$

\section{Antecedentes y justificación}

De acuerdo con el dictamen de creación de la INCO, el profesional de esta carrera da cuenta de las demandas y requerimientos de áreas como la industria, la empresa, la educación, las telecomunicaciones y diferentes ramas de la ingeniería, que se manifiestan en forma de necesidades relacionadas con herramientas computacionales, en donde el área principal de desempeño es el software de base (programas primordiales de la computadora) y los subsistemas digitales de redes, telecomunicación y computación, así como las técnicas modernas de creación y adaptación de grandes sistemas de cómputo. Además, se establece que el egresado de la INCO debe tener las competencias para:

1. Diseñar, construir y operar sistemas digitales aplicables a la tecnología computacional.

2. Diseñar y escribir sistemas de programación con alto grado de dificultad técnica, compiladores, sistemas operativos y redes de telecomunicación, con el fin de integrar sistemas de cómputo, medianos y grandes.

3. Desarrollar sistemas y encontrar soluciones creativas e innovadoras para resolver problemas relacionados con la administración confiable de los recursos, lo que le permite aumentar la eficiencia en la operación de sistemas de producción y agilizar el control y manejo de todo tipo de información.

4. Utilizar técnicas experimentales, analíticas y heurísticas para la solución de problemas relacionados con el hardware, el software y sus aplicaciones.

5. Aplicar conocimientos pertinentes en la identificación y solución sistemática de problemas prácticos en su área de especialización.

6. Analizar, juzgar y tomar posiciones con respecto al papel de las computadoras en el progreso de la ciencia, la tecnología y en la vida del ser humano.

Para verificar que la INCO está cumpliendo con lo estipulado en su currículo, tal y como se mencionó, ha sido objeto de evaluaciones externas por parte de lo que se conoce en México como organismos acreditadores. Hasta la fecha, la INCO ha sido evaluada en dos ocasiones, concretamente por el Consejo Nacional de Acreditación en Informática y Computación (Conaic) (A. E. López, comunicación personal, 7 de octubre, 2017). Cabe mencionar que dicho organismo es la instancia reconocida por el Copaes para evaluar y acreditar los programas educativos afines a la informática y la computación, a nivel medio superior, técnico superior universitario y superior (Consejo Nacional de Acreditación en Informática y Computación, 2018). 


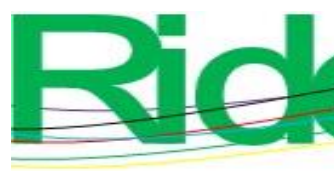

Revista Iberoamericana para la Investigación y el Desarrollo Educativo ISSN $2007-7467$

En cuanto a evaluaciones internas, la INCO no ha formado parte de este tipo de procesos ni de otro tipo de estudio o investigación con un propósito similar. Tal situación no es casualidad debido a que el CUR carece de una cultura de evaluación interna sistemática que se enfoque en mejorar los currículos (A. E. López, comunicación personal, 7 de octubre, 2017).

A pesar de que una evaluación curricular es muy amplia e involucra demasiadas variables, el modelo CIPP de Stufflebeam y Shinkfield (1987/2011) se ajustó perfectamente para llevar a cabo esta investigación. Este modelo permite evaluar un currículo de manera parcial o total, es decir, se puede utilizar una sola de sus etapas o se pueden combinar dos o más. Para los fines perseguidos en investigación se empleó únicamente la última etapa — la de producto-, ya que es la que hace posible valorar el nivel de correspondencia entre el currículo de la carrera y sus objetivos, estimar el nivel de satisfacción académica de los egresados e identificar fortalezas y debilidades de la carrera.

\section{Propósito del estudio}

El propósito de esta investigación fue evaluar el currículo de la carrera de ingeniería en Computación de una universidad mexicana para emitir un juicio con respecto al cumplimiento de los objetivos planteados en su currículo.

\section{Preguntas de investigación}

1. ¿Existe correspondencia entre el currículo de la INCO y los objetivos establecidos en el documento institucional que avala la creación del currículo?

2. ¿Cuál es el nivel de satisfacción académica de los egresados de la INCO?

3. ¿Cuáles son las fortalezas y debilidades de la INCO desde la perspectiva de los egresados?

\section{Materiales y método}

Con base en el propósito de la investigación, se optó por emplear un enfoque no experimental mixto; no experimental porque permite observar a un fenómeno (el currículo) sin alterar de manera intencional las variables; y mixto porque de este modo se logran recabar y analizar tanto datos cualitativos como cuantitativos indispensables para dar respuesta a las preguntas de investigación (Hernández, Fernández y Baptista, 2014). 


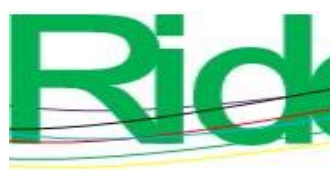

Revista Iberoamericana para la Investigación y el Desarrollo Educativo ISSN 2007 - 7467

\section{Participantes}

La población de esta investigación la constituyeron 86 egresados, cifra que corresponde a la suma total de hombres y mujeres, mayores de edad, que concluyeron satisfactoriamente la INCO en los últimos seis semestres (al momento de realizar el estudio). La muestra la conformaron 63 alumnos, número que se calculó a partir de la estimación de la proporción de la población, ya que esta es una técnica recurrente cuando la población es conocida o finita, y cuando se desea que el muestreo sea probabilístico o aleatorio (Arias, 2012). Para realizar dicho cálculo, dadas las condiciones, y de acuerdo con Del Cid, Méndez y Franco (2011), la fórmula más apropiada es la siguiente:

$$
n=\frac{Z^{2} P Q N}{E^{2}(N-1)+Z^{2} P Q}
$$

En donde:

$\mathrm{n}=$ Muestra

$\mathrm{Z}=$ Nivel de confianza o valor de significancia elegido (1.96)

$\mathrm{P}=$ Probabilidad de éxito $(0.05)$

$\mathrm{Q}=$ Probabilidad de fracaso $(0.95)$

$\mathrm{N}=$ Población (86)

$\mathrm{E}=$ Error máximo permitido (0.03)

Con un nivel de confianza (Z) esperado de $95 \%$, y con un error máximo permitido (E) de $3 \%$, al sustituir valores, la fórmula queda como sigue:

$$
n=\frac{(1.96)^{2}(0.05)(0.95)(86)}{(0.03)^{2}(86-1)+(1.96)^{2}(0.05)(0.95)}=60.59
$$

Es importante mencionar que aunque no es parte de la población como tal, el dictamen o documento que avala la creación del currículo (en adelante DACC) fue de vital trascendencia para el propósito perseguido, por lo que se consideró como una valiosa fuente de información escrita y, por ende, como participante. Este documento data del 29 de marzo de 2003, según los expedientes del CUR. Como se mencionó, en este se especifican los detalles de la creación de la INCO, tales como la justificación de su creación, sus objetivos, el perfil de egreso, la formación de los profesores, los servicios institucionales, las materias a cursar, entre otros. 

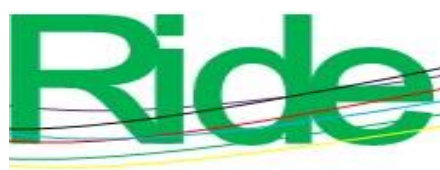

Revista Iberoamericana para la Investigación y el Desarrollo Educativo ISSN $2007-7467$

\section{Instrumentos}

Para dar respuesta a las preguntas de investigación se utilizaron dos cuestionarios y un grupo focal. A continuación, se describen tanto los instrumentos como el procedimiento para su validación:

\section{Cuestionario perfil de egreso}

El primero de los instrumentos se denominó cuestionario perfil de egreso (en adelante CPE). Este consta de 22 preguntas cerradas con distintas opciones de respuesta tipo Likert. Las preguntas de la 1 a la 17 presentan cinco opciones de respuesta, a saber: 1) no preparado, 2) poco preparado, 3) indeciso, 4) preparado y 5) mиy preparado. De la pregunta 18 a la 21 presentan otras cinco opciones de respuesta: 1) no desarrollado, 2) poco desarrollado, 3) indeciso, 4) desarrollado y 5) muy desarrollado. La pregunta final (número 22) presenta solamente dos posibles respuestas: 1) sí y 2) no. Al final de todas las preguntas, el participante dispone de un espacio en blanco para explicar el porqué de su respuesta. La carrera tiene dos orientaciones o especializaciones: 1) Software de Sistemas y 2) Sistemas Digitales. En ese sentido, cabe señalar que hay cuatro preguntas específicas por orientación. De la pregunta 10 a la 13 van dirigidas a alumnos con orientación en Software de Sistemas, y de la 14 a la 17 a aquellos con orientación en Sistemas Digitales.

El CPE se diseñó para obtener información sobre conocimientos, habilidades, valores y destrezas que los egresados pudieron adquirir durante su carrera. Con base en lo anterior, la estructura o disposición del instrumento corresponde a: 1) seis preguntas enfocadas a los conocimientos obtenidos, 2) once preguntas (tres generales y ocho particulares: cuatro por orientación) concernientes a las habilidades y destrezas adquiridas, 3) cuatro preguntas relacionadas con los valores y actitudes desarrollados, y 4) una pregunta final cuyo objetivo es recabar la opinión de los egresados para indagar si la carrera les proporciona las herramientas necesarias (conocimientos, habilidades, valores, destrezas y actitudes) para conseguir empleo. Esto último con base en el punto de vista de cada uno de ellos tras haber solicitado empleo en un campo afín a la carrera. 


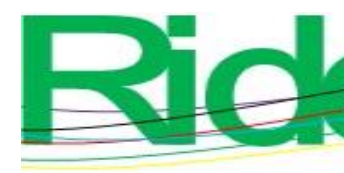

Revista Iberoamericana para la Investigación y el Desarrollo Educativo ISSN $2007-7467$

\section{Cuestionario formación académica}

El segundo instrumento se denominó cuestionario formación académica (en adelante CFA). Este se dividió en cuatro bloques, con un total de 22 preguntas: 20 cerradas y dos abiertas. Tanto en el primer bloque (de la pregunta 1 a la 7) como en el segundo (de la pregunta 8 a la 14) se evalúan en dos etapas. En primera instancia se evalúa la cobertura y posteriormente la calidad. A pesar de que este fragmento de la evaluación se hace en dos etapas, ambas presentan similares opciones de respuesta de tipo Likert: 1) mínima, 2) baja, (3) regular, 4) buena y 5) excelente.

En el tercer bloque (de la pregunta 15 a la 19) existen cinco opciones de respuesta tipo Likert: 1) mínimo, 2) bajo, 3) regular, 4) bueno y 5) excelente. A pesar de que este bloque puede parecer similar a los anteriores, hay dos diferencias importantes: en primer lugar, la evaluación no se hace en dos partes; en segundo lugar, al final de cada pregunta el participante dispone de un espacio en blanco para que explique el porqué de su respuesta.

El cuarto y último bloque consta de tres preguntas (20 a 22). Las dos primeras preguntas son abiertas, y la pregunta que da fin a este instrumento es cerrada.

El diseño del CFA permite indagar acerca de la experiencia de formación académica de los egresados de la carrera. Con base en lo anterior, la estructura o disposición del instrumento corresponde a: 1) siete preguntas enfocadas en identificar cómo evalúan los egresados aspectos materiales, académicos y administrativos; 2) siete preguntas enfocadas en identificar cómo los egresados evalúan aspectos particulares del diseño curricular; 3) cinco preguntas enfocadas a los aspectos particulares de los docentes, y 4) dos preguntas abiertas cuyo objetivo es recoger las sugerencias de cambio a la INCO con miras a mejorar la formación académica de las nuevas generaciones. Esto último desde el punto de vista de cada uno de ellos como egresados de la INCO.

\section{Validez y confiabilidad de los instrumentos}

Para establecer la confiabilidad y validez del CPE y el CFA, por la similitud, en ambos se siguió el mismo procedimiento. Primero se diseñó y aplicó un instrumento de validación de contenido y posteriormente se aplicó una prueba piloto. Los instrumentos de validación de contenido se denominaron VCPE o validación del cuestionario perfil de egreso y VCPE o validación del cuestionario formación académica. Tales instrumentos de validación se diseñaron con la finalidad de que expertos en el área de la docencia y la computación evaluaran 


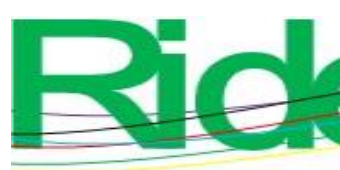

Revista Iberoamericana para la Investigación y el Desarrollo Educativo ISSN $2007-7467$

la relación entre las preguntas del CPE y el CFA con el propósito del estudio y las preguntas de investigación. Cabe destacar que los instrumentos contemplaron elementos clave, como 1) criterio, 2) pertinencia y 3) observaciones o sugerencias para cada pregunta.

El criterio se vinculó con distintos aspectos. En el caso del CPE, con la palabra clave que se relaciona con la primera pregunta de investigación, y representa los conocimientos, habilidades, valores, destrezas y capacidades que caracterizan al egresado de una profesión a partir del desempeño evidenciado durante su proceso formativo. En el caso del CFA, se vinculó con la palabra clave que se relaciona con la segunda pregunta de investigación, y representa aspectos particulares de la formación académica del egresado.

La pertinencia consistió en valorar si el contenido de la pregunta guardaba relación con el propósito del estudio y con la pregunta de investigación a la que pretendía dar respuesta el instrumento. El último elemento, observaciones o sugerencias, tuvo el propósito de tomar conciencia de los elementos factibles de modificarse, eliminarse o incluirse en el CPE y el CFA.

En total, cuatro expertos participaron en la validación de ambos instrumentos. Todos ellos con experiencia en la investigación de campo y la formación académica en áreas como tecnologías, computación, telecomunicaciones y educación. De manera individual e independiente, fueron entregados a los expertos los dos cuestionarios (CPE y CFA) y los dos instrumentos de validación (VCPE y VCFA). Antes de que iniciaran con el llenado del VCPE y el VCFA, se les solicitó que los leyeran en conjunto con el CPE y el CFA para resolver cualquier duda.

Para la prueba piloto se contó con la participación de 11 egresados de la carrera. A ellos se les hizo llegar tanto el CPE como el CFA a través de Google. Una vez aplicada la prueba piloto, para calcular el coeficiente de confiabilidad del CPE y del CFA, se recurrió a las medidas de coherencia o consistencia interna, específicamente a partir del alfa de Cronbach. De acuerdo con Hernández et al. (2014), además de ser este uno de los procedimientos más utilizados, permite calcular la confiabilidad a partir de una sola aplicación del instrumento de medición, y se calcula con base en la siguiente fórmula:

$$
\propto=\frac{K}{K-1}\left[1-\frac{\sum V_{i}}{V_{t}}\right]
$$


En donde:

$$
\begin{aligned}
& \propto=\text { Alfa de Cronbach } \\
& K=\text { Número de ítems (preguntas o reactivos) } \\
& V_{i}=\text { Varianza } \\
& V_{t}=\text { Varianza total }
\end{aligned}
$$

Con esta fórmula se obtienen resultados que van desde cero a uno; los valores más cercanos a cero son indicio de baja confiabilidad; en caso contrario, los más cercanos a uno son indicativo de una confiabilidad elevada (Hernández et al., 2014). Para calcular instantáneamente este valor se utilizó el software de análisis estadístico SPSS (Statistical Package for the Social Science). Después de introducir los datos en el programa, el nivel de confiabilidad resultante para el CPE fue de 0.810, mientras que para el CFA fue de 0.903.

Al final del proceso de validación, tanto el CPE como el CFA recibieron buenas críticas por parte de los expertos. Cabe señalar que se les hicieron cambios mínimos en cuestión de redacción; se modificaron en cuanto a forma sin ser necesario tocar aspectos de fondo. En el caso específico del CFA, por recomendación de los expertos, se reubicó una pregunta y se eliminaron otras dos por considerárseles poco pertinentes para el estudio.

\section{Guía de discusión}

El tercer instrumento se denomina guía de discusión (en adelante GD), y se diseñó para ser aplicado a un grupo focal conformado por egresados. La estructura de la GD contempla 1) bienvenida, 2) propósito de la sesión, 3) procedimiento para la realización de la técnica de investigación de grupo focal, 4) preguntas, 5) despedida y 6) agradecimiento.

Las preguntas contenidas en la GD pretenden identificar las fortalezas y debilidades del currículo de la carrera. Estas se formularon a partir de tres aspectos: 1) los objetivos que se establecen en el modelo CIPP (Stufflebeam y Shinkfield, 1987/2011), 2) la revisión de estudios donde se ha implementado la técnica de grupos de enfoque, y 3) la definición de fortaleza y debilidad. 


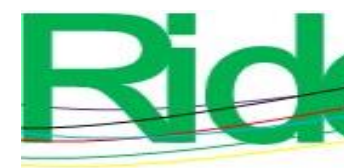

Revista Iberoamericana para la

Investigación y el Desarrollo Educativo

ISSN 2007 - 7467

\section{Validez y confiabilidad de la guía de discusión}

Para establecer la confiabilidad y validez de la GD se recurrió, en primera instancia, a la validación de constructos para establecer su relacionan con los conceptos a medir, lo que permitió determinar si el instrumento ayudaría, en este caso específico, a dar respuesta a la tercera pregunta de investigación. En resumen, y para tal efecto, solamente se validaron dos constructos: fortaleza y debilidad.

Durante esta etapa se solicitó el apoyo de cuatro expertos con experiencia en investigación de campo y formación académica en áreas como métodos de investigación y educación. En conjunto con ellos, se construyó una definición para cada uno de los términos, quedando de la siguiente manera: 1) el término fortaleza se refiere a todos los objetivos alcanzados por el currículo de la INCO, y que ayudan a diferenciarlo de otros programas educativos o currículos de la misma índole, y 2) el término debilidad se refiere a todos aquellos recursos humanos, materiales y tecnológicos que impiden que se logren los objetivos planteados en el currículo de la INCO.

En segunda instancia, se recurrió a la validación de contenido. En este sentido, Bautista (2009) afirma que un instrumento tiene validez siempre y cuando haya contemplado todos los aspectos importantes a medir, para lo cual primero se debe realizar, con anterioridad, una exhaustiva revisión de la literatura y, finalmente, una consulta con expertos para plantearles los aspectos que se quieren medir.

Por lo anterior se recurrió a cuatro expertos con experiencia en formación académica en el área de la computación. A ellos se les entregó, individual e independiente, el instrumento de validación para la guía de discusión (VGD), con la finalidad de validar los reactivos ahí presentados. Al final de todo el proceso, los resultados obtenidos determinaron que dichos reactivos eran pertinentes para evaluar los constructos de fortaleza y debilidad.

\section{Procedimiento}

Diseño

Para llevar a cabo la investigación se utilizó un enfoque no experimental mixto. De acuerdo con Hernández et al. (2014), en un estudio no experimental el investigador observa las situaciones ya existentes (no puede influir porque los eventos ya tuvieron lugar, al igual que sus efectos). El enfoque mixto se utilizó, de acuerdo con lo señalado por Creswell (2012), para poder 


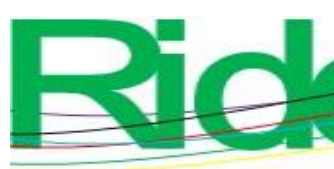

Revista Iberoamericana para la

Investigación y el Desarrollo Educativo

ISSN $2007-7467$

analizar datos tanto cualitativos como cuantitativos para una mejor comprensión del problema de investigación.

Lo anterior se entiende en el sentido de que el currículo de la INCO es una "situación existente", cuyas variables y efectos ya tuvieron lugar y repercusión en los egresados. Entonces, identificar esos efectos y repercusiones que ya tuvo el currículo en los egresados es lo que permitió determinar la correspondencia que existe entre el currículo de la carrera y los objetivos establecidos. Por su parte, el enfoque mixto es lo que permitió recabar y analizar las opiniones de los egresados con respecto a lo que fue su formación académica. Asimismo, con base en esta información, fue posible identificar las fortalezas y debilidades de la INCO.

En síntesis, la investigación se diseñó a partir de un procedimiento de tres etapas. En la tabla 1 se muestran esas fases con cada uno de los elementos que estuvieron presentes en ellas, es decir, los participantes, las técnicas de investigación, los instrumentos y la pregunta de investigación a la que dan respuesta.

Tabla 1. Etapas para la evaluación del currículo de la INCO

\begin{tabular}{|c|c|c|c|c|}
\hline Etapa & Participantes & $\begin{array}{l}\text { Técnica(s) de } \\
\text { investigación }\end{array}$ & Instrumento(s) & $\begin{array}{l}\text { Pregunta de } \\
\text { investigación }\end{array}$ \\
\hline 1 & $\begin{array}{l}\text { DACC y } 63 \text { egresados } \\
\text { de la INCO }\end{array}$ & $\begin{array}{l}\text { Análisis de } \\
\text { contenido y } \\
\text { cuestionario }\end{array}$ & Cuestionario (CPE) & Pregunta uno \\
\hline 2 & $\begin{array}{l}63 \text { egresados de la } \\
\text { INCO }\end{array}$ & Cuestionario & Cuestionario (CFA) & Pregunta dos \\
\hline 3 & $\begin{array}{l}13 \text { egresados de la } \\
\text { INCO }\end{array}$ & Grupo focal & $\begin{array}{l}\text { Guía de discusión } \\
\text { (GD) }\end{array}$ & Pregunta tres \\
\hline
\end{tabular}

Fuente: Elaboración propia

En este punto es importante señalar que los instrumentos, al igual que en la prueba piloto, se administraron vía Google Forms, y la discusión con el grupo focal se realizó de manera presencial en las instalaciones del campus. Para la sistematización de los datos, los resultados obtenidos de los instrumentos se exportaron a Microsoft Excel. En cuanto a los resultados de la discusión, se grabaron y posteriormente se capturaron también en Microsoft Excel para su categorización. 


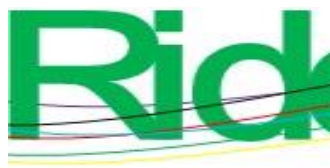

Revista Iberoamericana para la Investigación y el Desarrollo Educativo ISSN 2007 - 7467

\section{Análisis de los datos}

Para el análisis de datos se siguió exactamente el mismo orden que en la tabla 1. Esta fase también se dividió en tres etapas, cada una de las cuales obedece a la secuencia en que se presentaron las preguntas de investigación; es decir, el análisis de datos se dividió también en tres etapas. A continuación, para mejor comprensión del proceso de análisis de los datos, se explica el tratamiento que se dio a cada uno de los instrumentos en su respectiva etapa.

Etapa 1. Esta etapa se llevó a cabo en dos tiempos: primero se analizó el DACC y después el CPE. Se debe recordar que en esta etapa se buscó dar respuesta a la primera pregunta de investigación, la que se refiere a la correspondencia entre el currículo de la INCO y los objetivos establecidos en DACC.

El DACC, por su naturaleza, se catalogó como un documento institucional (Fernández, 2002). Por esta razón, primero se llevó a cabo un análisis de contenido, específicamente del tipo descriptivo que, según lo establece López (2002), es indispensable al momento de identificar los componentes básicos de un documento a través de un proceso riguroso de medición.

Posterior al análisis del DACC, se hizo un análisis estadístico descriptivo de las preguntas cerradas del CPE con la finalidad de identificar el desarrollo de conocimientos, destrezas, habilidades, actitudes y valores de los egresados, partiendo de la media, la moda y la desviación estándar de cada ítem. Al respecto, Münch y Ángeles (2009/2011) confirman que la estadística descriptiva es una técnica que permite organizar y resumir los datos cuantitativos. Ellos señalan también que con esta técnica es posible analizar individualmente cada pregunta de un instrumento para, posteriormente, analizarlo todo en conjunto. Finalmente, también se llevó a cabo un análisis de contenido de los porqués o de los argumentos de cada una de sus respuestas a las preguntas cerradas.

Etapa 2. En la segunda etapa, con los datos recolectados a partir del instrumento CFA, se buscó dar respuesta a la segunda de las preguntas de investigación, la que se refiere al nivel de satisfacción académica de los egresados de la INCO. En esta ocasión, por la similitud del CFA con el CPE, los datos recibieron el mismo trato. A partir de las preguntas cerradas se hizo un análisis estadístico descriptivo para poder identificar el nivel de satisfacción de los egresados sobre aspectos materiales, académicos y administrativos. De las preguntas abiertas se generó también un análisis de contenido, del mismo modo que se hizo con los porqués de cada una de las respuestas a las preguntas cerradas. 

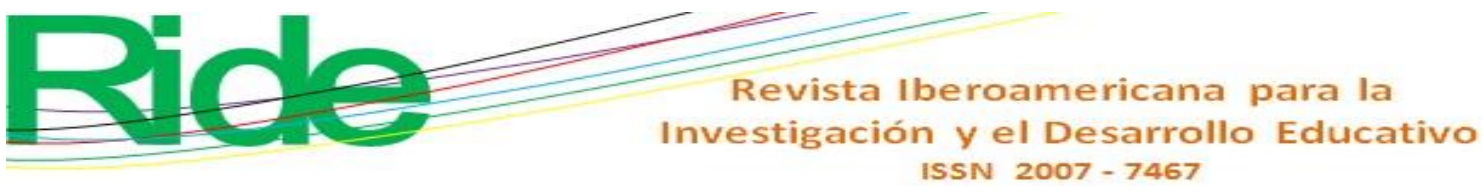

Etapa 3. La última etapa contempló el análisis de datos recolectados a partir de la guía de discusión o GD empleada durante la sesión del grupo focal. La pregunta de investigación que se buscó responder es la que se refiere a las fortalezas y debilidades de la INCO. Para ello, como técnica analítica se llevó a cabo un análisis secuencial de discurso que, como lo establece Flick (2004), se centra en los recuerdos, descripciones y/o formulaciones de los participantes, y los reorienta a los temas (fortalezas y debilidades) del contexto analizado.

\section{Resultados}

\section{Pregunta de investigación uno}

La primera pregunta se refiere a la correspondencia entre el currículo de la INCO y los objetivos establecidos en el DACC. Para responderla, se llevó a cabo un proceso de dos fases. En la primera se hizo un análisis de contenido del DACC y, como resultado del análisis, se establecieron tres categorías o dimensiones basadas en el perfil de egreso de los alumnos de la INCO, a saber: 1) conocimientos, 2) habilidades y destrezas, 3) actitudes y valores. En la segunda fase se recuperaron los datos obtenidos a partir del análisis descriptivo de los ítems del CPE.

A continuación, en la tabla 2, se presenta el resultado del análisis estadístico descriptivo del CPE. Los datos se desglosaron por ítem y los ítems se agruparon por dimensión. 


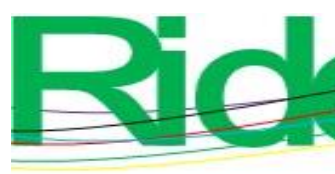

Tabla 2. Análisis estadístico del cuestionario perfil de egreso (CPE)

\begin{tabular}{|c|c|c|c|c|}
\hline Dimensión & Ítem & Media & Moda & $\begin{array}{l}\text { Desviación } \\
\text { estándar }\end{array}$ \\
\hline \multirow{6}{*}{ Conocimientos } & 1. Arquitectura de computadoras & 3.70 & 4.00 & 0.96 \\
\hline & 2. Redes & 3.35 & 4.00 & 0.99 \\
\hline & 3. Programación & 3.56 & 4.00 & 1.07 \\
\hline & $\begin{array}{l}\text { 4. Tratamiento de la información } \\
\text { (estructura de datos, estructura de } \\
\text { archivos) }\end{array}$ & 3.54 & 4.00 & 0.91 \\
\hline & $\begin{array}{l}\text { 5. Interacción hombre-máquina (gráficas } \\
\text { por computadora, multimedia) }\end{array}$ & 3.22 & 4.00 & 1.10 \\
\hline & $\begin{array}{l}\text { 6. Entorno social (comunicación oral y } \\
\text { escrita, redacción, análisis contable, } \\
\text { propiedad intelectual) }\end{array}$ & 3.41 & 4.00 & 1.07 \\
\hline \multirow{3}{*}{$\begin{array}{l}\text { Habilidades y } \\
\text { destrezas } \\
\text { [generales] }\end{array}$} & $\begin{array}{l}\text { 7. Planeación, diseño, administración, } \\
\text { implementación y producción de sistemas } \\
\text { que permiten aumentar la eficiencia de } \\
\text { operación de las organizaciones }\end{array}$ & 3.16 & 4.00 & 1.11 \\
\hline & $\begin{array}{l}\text { 8. Uso de técnicas experimentales, } \\
\text { analíticas e innovadoras para la solución } \\
\text { de problemas (a través de hardware y } \\
\text { software) }\end{array}$ & 3.27 & 4.00 & 1.11 \\
\hline & $\begin{array}{l}\text { 9. Diseño e implementación de } \\
\text { arquitectura de computadora y desarrollo } \\
\text { del software de aplicación que le compete }\end{array}$ & 3.48 & 4.00 & 1.06 \\
\hline \multirow{4}{*}{$\begin{array}{l}\text { Habilidades y } \\
\text { destrezas } \\
\text { [Software de } \\
\text { Sistemas] }\end{array}$} & $\begin{array}{l}\text { 10. Diseño y desarrollo de sistemas de } \\
\text { software de base (los sistemas de } \\
\text { programación primordiales en una } \\
\text { computadora) }\end{array}$ & 3.48 & 4.00 & 0.92 \\
\hline & $\begin{array}{l}\text { 11. Habilidad para interactuar con } \\
\text { subsistemas digitales y de } \\
\text { telecomunicaciones (redes) }\end{array}$ & 3.31 & 3.00 & 1.08 \\
\hline & $\begin{array}{l}\text { 12. Diseño e implementación de sistemas } \\
\text { operativos }\end{array}$ & 3.13 & 4.00 & 1.01 \\
\hline & $\begin{array}{l}\text { 13. Diseño y concepción de nuevos } \\
\text { lenguajes de programación, así como } \\
\text { construcción de compiladores } \\
\text { (traductores) }\end{array}$ & 2.63 & 3.00 & 1.19 \\
\hline \multirow{3}{*}{$\begin{array}{l}\text { Habilidades y } \\
\text { destrezas } \\
\text { [Sistemas } \\
\text { Digitales] }\end{array}$} & $\begin{array}{l}\text { 14. Diseño, construcción, instalación, } \\
\text { operación y mantenimiento a sistemas } \\
\text { digitales e interfaces }\end{array}$ & 3.09 & 4.00 & 1.22 \\
\hline & $\begin{array}{l}\text { 15. Diseño e implementación de } \\
\text { herramientas de software necesarias para } \\
\text { el manejo del hardware }\end{array}$ & 2.73 & 3.00 & 1.27 \\
\hline & $\begin{array}{l}\text { 16. Concepción, diseño y construcción de } \\
\text { hardware computacional que satisfaga } \\
\text { definiciones de funcionabilidad y fines } \\
\text { específicos }\end{array}$ & 2.55 & 4.00 & 1.29 \\
\hline
\end{tabular}




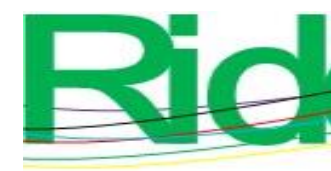

Revista Iberoamericana para la Investigación y el Desarrollo Educativo ISSN $2007-7467$

\begin{tabular}{|l|l|c|c|c|}
\hline & $\begin{array}{l}\text { 17. Concepción, diseño y construcción de } \\
\text { sistemas de transmisión y comunicación } \\
\text { de información (redes) }\end{array}$ & 2.82 & 2.00 & 1.08 \\
\hline & $\begin{array}{l}\text { 18. Responsabilidad, profesionalismo y } \\
\text { búsqueda de la calidad }\end{array}$ & 3.97 & 4.00 & 0.74 \\
\cline { 2 - 5 } & $\begin{array}{l}\text { 19. Actitud de superación continua } \\
\text { (especialmente en el área de computación) }\end{array}$ & 4.00 & 4.00 & 0.92 \\
\cline { 2 - 5 } $\begin{array}{l}\text { Actitudes y } \\
\text { valores }\end{array}$ & $\begin{array}{l}\text { 20. Disciplina, tenacidad y autoexigencia } \\
\text { para alcanzar objetivos personales y } \\
\text { profesionales }\end{array}$ & 4.11 & 4.00 & 0.67 \\
\hline $\begin{array}{l}\text { 21. Creatividad para diseñar y desarrollar } \\
\text { sistemas que atiendan las necesidades } \\
\text { propias del trabajo }\end{array}$ & 3.75 & 4.00 & 0.95 \\
\hline
\end{tabular}

Fuente: Elaboración propia

Es importante mencionar que las respuestas de los ítems se reunieron en tres grupos: positivas, neutras y negativas. Como respuestas negativas se agruparon las escalas 1 y 2 (no preparado/poco preparado), mientras que las escalas 4 y 5 (preparado/muy preparado) se agruparon como respuestas positivas, tal y como se aprecia en la tabla 3.

Tabla 3. Porcentaje acumulado por tipo de respuesta para cada dimensión

\begin{tabular}{|l|c|c|c|}
\hline Dimensión & $\begin{array}{c}\text { No preparado / } \\
\text { Poco preparado }\end{array}$ & Indeciso & $\begin{array}{c}\text { Preparado / } \\
\text { Muy } \\
\text { preparado }\end{array}$ \\
\hline Conocimientos & 20 & 21 & 59 \\
\hline Habilidades y destrezas [generales] & 24 & 24 & 52 \\
\hline $\begin{array}{l}\text { Habilidades y destrezas [Software de } \\
\text { Sistemas] }\end{array}$ & 28 & 30 & 42 \\
\hline Habilidades y destrezas [Sistemas Digitales] & 45 & 18 & 36 \\
\hline Actitudes y valores & 7 & 12 & 81 \\
\hline
\end{tabular}

Fuente: Elaboración propia

La dimensión de "conocimientos" señala que el egresado deberá tener dominio teóricopráctico en áreas tales como arquitectura de computadoras, redes, programación, tratamiento de la información, interacción hombre-máquina y entorno social. Aquí, el CPE arrojó 59\% de respuestas positivas, $20 \%$ fueron negativas y el $21 \%$ neutras. A partir de estos resultados, se encontró que 1) los egresados sí están siendo preparados con respecto al dominio teóricopráctico en las áreas que se estipulan en el DACC, y 2) las áreas a las que se hace mención son a) la arquitectura de computadoras, b) las redes, c) la programación, d) el tratamiento de la información, e) la interacción hombre-máquina, y f) el entorno social. 


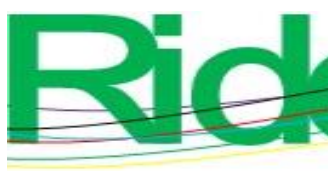

Revista Iberoamericana para la Investigación y el Desarrollo Educativo ISSN $2007-7467$

La dimensión de "habilidades y destrezas" se describe en tres vertientes: generales, particulares de la orientación Software de Sistemas, y particulares de la orientación en Sistemas Digitales. Acerca de las habilidades y destrezas generales se señala que deberán abarcar la planeación, el diseño, la administración, la implementación y la producción de sistemas; el uso de técnicas experimentales, analíticas e innovadoras para la solución de problemas (a través de hardware y software); y el diseño e implementación de arquitectura de computadoras y desarrollo de software. Para esta dimensión, el CPE arrojó $52 \%$ de respuestas positivas, $24 \%$ negativas y $24 \%$ neutras.

A partir de los hallazgos, se encontró que los egresados de la INCO sí están siendo preparados con respecto de las habilidades y destrezas propias del perfil de la carrera, tal y como se estipula en el DACC. Las habilidades y destrezas a las que se hace referencia son: a) la planeación, el diseño, la administración, la implementación y la producción de sistemas, b) las técnicas experimentales, analíticas e innovadoras para la solución de problemas, y c) el diseño e implementación de arquitectura de computadora y desarrollo de software.

En la orientación de Software de Sistemas, se señala que los egresados deberán desarrollarse en cuanto al diseño y desarrollo de sistemas de software de base; la interacción con subsistemas digitales y de telecomunicaciones; el diseño e implementación de sistemas operativos; y el diseño y concepción de nuevos lenguajes de programación, así como construcción de traductores. Aquí, el CPE arrojó $42 \%$ de respuestas positivas, $28 \%$ negativas y $30 \%$ neutras. A partir de estos resultados, se encontró que 1) los egresados sí están siendo preparados con respecto de las habilidades y destrezas propias del perfil de egreso con esta orientación, tal y como se estipula en el DACC; 2) las habilidades y destrezas en las que se les prepara son: a) el diseño y el desarrollo de sistemas de software de base, b) la interacción con subsistemas digitales y de telecomunicaciones, c) el diseño e implementación de sistemas operativos; y 3) no se les está preparando adecuadamente en cuanto al diseño y la concepción de nuevos lenguajes de programación, así como en la construcción de traductores.

En la orientación en Sistemas Digitales, se señala que los egresados deberán desarrollarse en cuanto al diseño, la construcción, la instalación, la operación y el mantenimiento a sistemas digitales e interfaces; el diseño e implementación de herramientas de software necesarias para el manejo del hardware; la concepción, el diseño y la construcción de hardware computacional que sea funcional y para fines específicos; y la concepción, el diseño y la construcción de sistemas de transmisión y comunicación de información. En este caso, el 

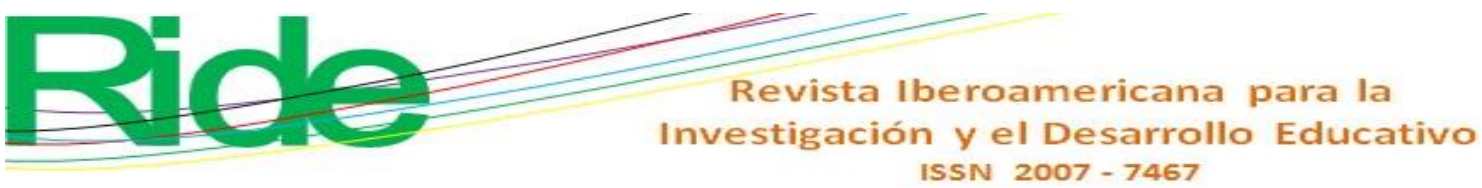

CPE arrojó un total de $45 \%$ de respuestas negativas, $36 \%$ positivas y $18 \%$ neutras. A partir de estos resultados, se encontró que 1) los egresados de esta carrera no están siendo preparados con respecto de las habilidades y destrezas propias del perfil de egreso con esta orientación, tal y como se estipula en el DACC; 2) las habilidades y destrezas en las que no se les prepara son: a) diseño e implementación de herramientas de software necesarias para el manejo del hardware, b) concepción, diseño y construcción de hardware computacional que sea funcional y para fines específicos, y c) concepción, diseño y construcción de sistemas de transmisión y comunicación de información. Solamente se les está preparando en lo que respecta a diseño, construcción, instalación, operación y mantenimiento a sistemas digitales e interfaces.

La dimensión de "actitudes y valores" señala que el egresado de la INCO deberá desarrollar actitudes y valores tales como responsabilidad, profesionalismo y búsqueda de la calidad, superación continua, disciplina, tenacidad y autoexigencia para alcanzar objetivos personales y profesionales, así como creatividad. Los resultados arrojaron que $81 \%$ de las respuestas fueron positivas. A partir de estos resultados, se encontró que 1) los egresados están desarrollando actitudes y valores propios del perfil de egreso de la INCO, tal y como se estipula en el DACC, y 2) las actitudes y valores a las que se hace mención son a) responsabilidad, profesionalismo y búsqueda de la calidad, b) superación continua, c) disciplina, tenacidad y autoexigencia, y d) creatividad para diseñar y desarrollar sistemas.

\section{Pregunta de investigación dos}

A través del cuestionario formación académica o CFA, se buscó dar respuesta a la segunda pregunta de investigación. A partir de esta pregunta se buscó identificar el nivel de satisfacción académica de los egresados de la INCO. La evaluación que se hizo con este instrumento contempló diversos aspectos que se agruparon en tres categorías:

\section{Categoría uno: aspectos materiales, académicos y administrativos}

En esta los egresados evaluaron la cobertura y la calidad de a) las instalaciones físicas, b) el equipo de cómputo, c) el equipo especializado para prácticas según su orientación, d) el servicio de biblioteca, e) el acervo bibliográfico, f) los servicios administrativos, y g) los servicios complementarios. 


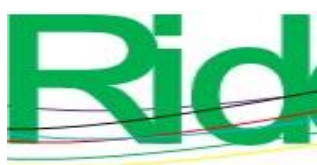

Revista Iberoamericana para la Investigación y el Desarrollo Educativo ISSN $2007-7467$

\section{Categoría dos: aspectos particulares del diseño curricular}

En esta se evaluó la cobertura y la calidad de a) los contenidos teóricos, b) los contenidos prácticos, c) el contenido social, d) las prácticas profesionales, e) la formación integral, f) la tutoría académica, y g) la movilidad estudiantil.

\section{Categoría tres: aspectos particulares de los docentes}

En esta, de manera general, se evaluó a) el dominio del tema o materia, b) las competencias didácticas, c) el uso de materiales didácticos, d) el uso de tecnologías de la información y comunicación, y e) la disponibilidad fuera de las aulas.

A continuación, en la tabla 4, se presenta el resultado del análisis estadístico descriptivo del CFA. Los datos se describen por ítem y para cada ítem hay una columna para cobertura y otra para calidad, además, los ítems están agrupados por categoría. La última categoría, acerca de los aspectos particulares de los docentes, no se evaluó a partir de cobertura y calidad, sino tomando en cuenta la experiencia de los docentes, sus competencias didácticas, el uso de materiales didácticos diversificado y actual, el uso de tecnologías y su disponibilidad fuera de las aulas y horarios de clase. 


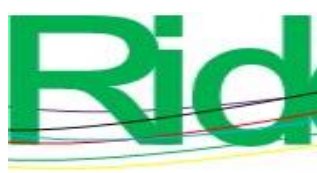

Tabla 4. Análisis estadístico del cuestionario formación académica (CFA)

\begin{tabular}{|c|c|c|c|c|c|c|c|}
\hline \multirow[b]{2}{*}{ Aspecto } & \multirow[b]{2}{*}{ Ítem } & \multicolumn{3}{|c|}{ Cobertura } & \multicolumn{3}{|c|}{ Calidad } \\
\hline & & 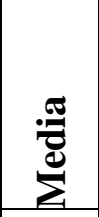 & $\frac{\pi}{\sigma_{0}^{\circ}}$ & 递䨌 & 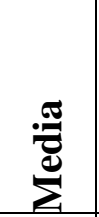 & 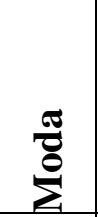 & 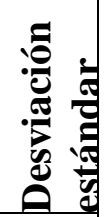 \\
\hline \multirow{7}{*}{$\begin{array}{l}\text { Materiales, } \\
\text { académicos } \\
\text { y } \\
\text { administrativ } \\
\text { os }\end{array}$} & $\begin{array}{l}\text { 1. Instalaciones físicas (laboratorios, salones } \\
\text { de clase, biblioteca, auditorios) }\end{array}$ & 3.65 & 4 & 0.77 & 3.57 & 4.00 & 0.73 \\
\hline & 2. Equipo de cómputo & 3.78 & 4 & 0.75 & 3.49 & 4.00 & 0.88 \\
\hline & $\begin{array}{l}\text { 3. Equipo especializado para prácticas según } \\
\text { tu orientación o especialidad (sistemas } \\
\text { digitales o software de sistemas) }\end{array}$ & 3.03 & 3 & 0.97 & 3.03 & 3.00 & 0.98 \\
\hline & $\begin{array}{l}\text { 4. Servicio de biblioteca (atención y } \\
\text { disponibilidad del personal) }\end{array}$ & 3.92 & 4 & 0.77 & 3.86 & 4.00 & 0.82 \\
\hline & $\begin{array}{l}\text { 5. Colección de libros de biblioteca } \\
\text { (actualidad y disponibilidad) }\end{array}$ & 3.62 & 4 & 0.97 & 3.60 & 4.00 & 0.99 \\
\hline & $\begin{array}{l}\text { 6. Servicios administrativos ofrecidos por la } \\
\text { institución (coordinación de carrera, control } \\
\text { escolar, servicio social, becas, otras unidades } \\
\text { y directivos) }\end{array}$ & 3.97 & 5 & 0.95 & 4.03 & 5.00 & 0.95 \\
\hline & $\begin{array}{l}\text { 7. Servicios complementarios (servicios } \\
\text { médicos, cafetería, papelería, } \\
\text { estacionamiento, seguridad, etc.) }\end{array}$ & 3.52 & 4 & 0.98 & 3.46 & 3.00 & 0.98 \\
\hline \multirow{7}{*}{$\begin{array}{l}\text { Diseño } \\
\text { curricular }\end{array}$} & 8. Contenidos teóricos & 3.62 & 4 & 0.89 & 3.49 & 3.00 & 0.95 \\
\hline & 9. Contenidos prácticos & 3.21 & 3 & 1.00 & 3.30 & 3.00 & 0.94 \\
\hline & $\begin{array}{l}\text { 10. Contenido social (materias del plan de } \\
\text { estudios que responden a las necesidades que } \\
\text { demanda el mundo laboral) }\end{array}$ & 2.98 & 3 & 1.01 & 3.11 & 3.00 & 1.02 \\
\hline & $\begin{array}{l}\text { 11. Prácticas profesionales (empresas u } \\
\text { opciones donde se pueden realizar las } \\
\text { prácticas) }\end{array}$ & 3.43 & 4 & 1.17 & 3.46 & 4.00 & 1.15 \\
\hline & $\begin{array}{l}\text { 12. Formación integral (eventos académicos, } \\
\text { deportivos, culturales, etc.) }\end{array}$ & 3.56 & 4 & 0.96 & 3.57 & 4.00 & 0.95 \\
\hline & 13. Tutoría académica durante los estudios & 3.24 & 3 & 1.03 & 3.32 & 3.00 & 1.03 \\
\hline & $\begin{array}{l}\text { 14. Movilidad estudiantil (oportunidades } \\
\text { para cursar parte de la carrera en otra } \\
\text { universidad, a nivel nacional o internacional) }\end{array}$ & 3.32 & 3 & 0.91 & 3.35 & 4.00 & 0.92 \\
\hline \multirow{3}{*}{ Docentes } & $\begin{array}{l}\text { 15. Dominio que tienen los profesores del } \\
\text { tema o materia (experiencia) }\end{array}$ & 3.41 & 3 & 0.99 & & & \\
\hline & $\begin{array}{l}\text { 16. Competencias didácticas de los } \\
\text { profesores (recursos y estrategias empleados } \\
\text { para enseñar; habilidad para dar clases) }\end{array}$ & 3.38 & 4 & 0.92 & & & \\
\hline & $\begin{array}{l}\text { 17. Uso de materiales didácticos } \\
\text { proporcionados por los profesores en clase }\end{array}$ & 3.67 & 4 & 0.84 & & & \\
\hline
\end{tabular}




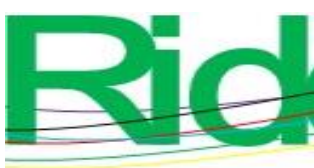

\begin{tabular}{|l|l|l|l|l|l|l|l|}
\hline $\begin{array}{l}\text { (textos impresos o digitales, videos, } \\
\text { presentaciones con diapositivas, etc.) }\end{array}$ & & & & & & \\
\hline $\begin{array}{l}\text { 18. Uso de tecnologías de la información y } \\
\text { comunicación por parte de los profesores } \\
\text { para impartir clases }\end{array}$ & 3.78 & 4 & 0.81 & & & \\
\hline $\begin{array}{l}\text { 19. Disponibilidad de los profesores fuera de } \\
\text { las aulas y de los horarios de clase } \\
\text { (asesorías) }\end{array}$ & 3.56 & 3 & 1.12 & & & \\
\hline
\end{tabular}

Fuente: Elaboración propia

Del mismo modo que se hizo con el CPE, también se agruparon las respuestas en tres grupos: positivas, neutras y negativas. Como respuestas negativas se agruparon las escalas $1 \mathrm{y}$ 2 (mínimo/bajo), mientras que las escalas 4 y 5 (buenolexcelente) se agruparon como respuestas positivas, tal y como se aprecia en la tabla 5.

Tabla 5. Porcentaje acumulado por tipo de respuesta para cobertura y calidad de cada aspecto

\begin{tabular}{|l|c|c|c|}
\hline Aspecto & $\begin{array}{c}\text { Mínimo / } \\
\text { Bajo }\end{array}$ & $\begin{array}{c}\text { Regula } \\
\text { r }\end{array}$ & $\begin{array}{c}\text { Bueno / } \\
\text { Excelente }\end{array}$ \\
\hline $\begin{array}{l}\text { Materiales, académicos y administrativos } \\
\text { [cobertura] }\end{array}$ & 10 & 32 & 58 \\
\hline $\begin{array}{l}\text { Materiales, académicos y administrativos } \\
\text { [calidad] }\end{array}$ & 11 & 32 & 56 \\
\hline Diseño curricular [cobertura] & 20 & 35 & 45 \\
\hline Diseño curricular [calidad] & 18 & 36 & 46 \\
\hline Docentes & 13 & 33 & 54 \\
\hline
\end{tabular}

Fuente: Elaboración propia

En lo que respecta a los "aspectos materiales, académicos y administrativos", la cobertura se posicionó en $58 \%$ de respuestas positivas, y la calidad obtuvo $56 \%$ de respuestas positivas. En relación con los "aspectos particulares del diseño curricular", la cobertura obtuvo $45 \%$ de respuestas positivas, y la calidad $46 \%$. Finalmente, en lo concerniente a los "aspectos particulares de los docentes", los egresados los evaluaron con $58 \%$ respuestas positivas.

\section{Pregunta de investigación tres}

La tercera y última pregunta de investigación se diseñó para identificar las fortalezas y debilidades de la INCO desde la perspectiva de los egresados. La respuesta a esta pregunta se obtuvo a partir de la guía de discusión o GD, que se aplicó a un grupo focal compuesto por 13 egresados de ambos sexos y de diversas generaciones. 


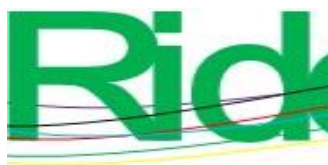

Revista Iberoamericana para la Investigación y el Desarrollo Educativo ISSN $2007-7467$

Una moderadora llevó a cabo la discusión en donde tomó nota y grabó el audio de la sesión. Con el propósito de conservar absoluta imparcialidad y para garantizar el anonimato de los participantes, la profesora moderadora era ajena a la carrera.

Tras recolectar las opiniones que se suscitaron durante una discusión que duró alrededor de dos horas, y después de analizar las notas de la moderadora y la grabación, se encontró que los egresados consideran como las dos principales fortalezas de la INCO: 1) el diseño de la malla curricular, ya que mencionaron que la forma como se estructuró es lo que más les beneficia al finalizar la carrera, porque, de esta manera, pueden realizar sus prácticas profesionales al concluir todos sus créditos, sin tener que cursar un semestre adicional, 2) las prácticas profesionales, ya que expresaron que estas significaron egresar de la carrera con un trabajo asegurado en el mismo lugar donde practicaron.

Como las principales debilidades de la carrera, los egresados señalaron a la planta docente y el equipo e infraestructura del campus. Se entiende que, para ellos, los docentes deberían tener más desarrolladas sus habilidades duras, es decir, el dominio de los temas de las materias que imparten, y el desarrollo de sus competencias en el uso de recursos y estrategias didácticas.

Del equipo e infraestructura, se entiende que no son los más apropiados y modernos. Los resultados señalaron que el equipo especializado para prácticas de laboratorio en ambas orientaciones o especialidades de la carrera no cumple con los estándares esperados tanto en cobertura como calidad.

\section{Conclusiones}

A partir de los resultados obtenidos (y respondiendo a la primera pregunta de investigación: ¿existe correspondencia entre el currículo de la INCO y los objetivos establecidos en el documento institucional que avala la creación del currículo?), se determinó que sí existe correspondencia entre los logros de la ingeniería en Computación y los objetivos planteados en el currículo, porque sí se están desarrollando los conocimientos, habilidades y destrezas, actitudes y valores que se estipulan en el perfil de egreso de la carrera.

No obstante, hay dos aspectos por mejorar para que la INCO logre todos sus objetivos propuestos. Por una parte, en la orientación de Software de Sistemas, se requiere que los alumnos logren el desarrollo de habilidades y destrezas concernientes al diseño y concepción de nuevos lenguajes de programación. Por otra, y en donde hay que poner mayor atención, se 


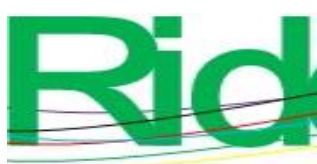

Revista Iberoamericana para la Investigación y el Desarrollo Educativo ISSN $2007-7467$

requiere lograr que los alumnos, de la orientación de Sistemas Digitales, desarrollen habilidades y destrezas en a) diseño e implementación de herramientas de software necesarias para el manejo del hardware, b) concepción, diseño y construcción de hardware que sea funcional y para fines específicos, y c) concepción, diseño y construcción de sistemas de transmisión y comunicación de información.

En términos generales, los resultados fueron positivos; no obstante, como ya se mencionó en el párrafo anterior, existen focos rojos que requieren especial atención. La tabla 6 ayuda a tener un mejor panorama en cuanto a la correspondencia entre los logros de la carrera y los objetivos planteados en su currículo, es decir, lo que el currículo está logrando y lo que no. 
Tabla 6. Resumen de los resultados de la primera pregunta de investigación

\begin{tabular}{|c|c|}
\hline Conocimientos (dominio teórico práctico en...) & $\begin{array}{c}\text { ¿Se } \\
\text { desarrolla? }\end{array}$ \\
\hline Arquitectura de computadoras & Sí \\
\hline Redes & Sí \\
\hline Programación & Sí \\
\hline Tratamiento de la información & Sí \\
\hline Interacción hombre-máquina & Sí \\
\hline Entorno social & Sí \\
\hline \multicolumn{2}{|l|}{ Habilidades y destrezas [generales] } \\
\hline Planeación, diseño, administración, implementación y producción de sistemas & Sí \\
\hline $\begin{array}{l}\text { Técnicas experimentales, analíticas e innovadoras para la solución de } \\
\text { problemas }\end{array}$ & Sí \\
\hline $\begin{array}{l}\text { Diseño e implementación de arquitectura de computadora y desarrollo de } \\
\text { software }\end{array}$ & Sí \\
\hline \multicolumn{2}{|l|}{ Habilidades y destrezas [Software de Sistemas] } \\
\hline Diseño y desarrollo de sistemas de software de base & Sí \\
\hline Interacción con subsistemas digitales y de telecomunicaciones & Sí \\
\hline Diseño e implementación de sistemas operativos & Sí \\
\hline Diseño y concepción de nuevos lenguajes de programación & No \\
\hline \multicolumn{2}{|l|}{ Habilidades y destrezas [Sistemas Digitales] } \\
\hline $\begin{array}{l}\text { Diseño e implementación de herramientas de software necesarias para el } \\
\text { manejo del hardware }\end{array}$ & No \\
\hline $\begin{array}{l}\text { Concepción, diseño y construcción de hardware que sea funcional y para fines } \\
\text { específicos }\end{array}$ & No \\
\hline $\begin{array}{l}\text { Concepción, diseño y construcción de sistemas de transmisión y comunicación } \\
\text { de información }\end{array}$ & No \\
\hline $\begin{array}{l}\text { Diseño, construcción, instalación, operación y mantenimiento a sistemas } \\
\text { digitales e interfaces }\end{array}$ & Sí \\
\hline \multicolumn{2}{|l|}{ Actitudes y valores } \\
\hline Responsabilidad, profesionalismo y búsqueda de la calidad & Sí \\
\hline Superación continua & Sí \\
\hline Disciplina, tenacidad y autoexigencia & Sí \\
\hline Creatividad (para diseñar y desarrollar sistemas) & Sí \\
\hline
\end{tabular}

Fuente: Elaboración propia

Respondiendo a la segunda pregunta de investigación (¿cuál es el nivel de satisfacción académica de los egresados de la INCO?), y a partir de los resultados obtenidos, se concluyó que el nivel de satisfacción se ubica en el rango entre regular y alto, pues se ubicó en 3.5 la media general en una escala que abarca los siguientes parámetros: 1) mínimo, 2) bajo, 3) regular, 4) alto, y 5) muy alto.

Lo menos satisfactorio para los egresados se relaciona con el diseño curricular. Para ellos, la cobertura (en el plan de estudios) en cuanto a materias específicas que responden a las necesidades que demanda el mundo laboral es lo que menos favorece al plan de estudios. 


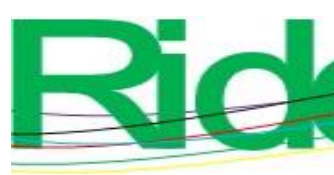

Revista Iberoamericana para la

Investigación y el Desarrollo Educativo

ISSN $2007-7467$

Ubicándose en 2.98, la media en este aspecto fue la más baja de todas. Dicho con otras palabras, el nivel de satisfacción se ubicó entre bajo y regular.

Finalmente, en respuesta a tercera pregunta de investigación (¿cuáles son las fortalezas y debilidades de la INCO desde la perspectiva de los egresados?), y aunque puede parecer contradictorio con lo que se dijo en el párrafo anterior, para los egresados el diseño de la malla curricular es la principal fortaleza de la carrera. Las prácticas profesionales es la otra fortaleza que ven los egresados en la INCO. Asimismo, se concluye como las principales debilidades de la carrera la planta docente y el equipo e infraestructura del campus.

En conclusión, las herramientas (conocimientos, habilidades y destrezas, actitudes y valores) que está proporcionando la INCO a sus alumnos son un factor decisivo para que al egresar logren emplearse en el ramo de la computación. Sin embargo, sería pertinente adentrarse aún más en el currículo de la INCO.

Por una parte, es necesario evaluar el currículo a partir de las tres fases restantes del modelo CIPP: contexto, entrada y proceso. Hay que recordar que la presente evaluación se llevó a cabo en la última etapa del modelo: producto. Una evaluación completa del currículo permitiría a las autoridades a cargo de la INCO una mejor toma de decisiones, más eficientes y eficaces.

Establecer un proceso de evaluaciones continuas y sistemáticas del currículo permitiría recabar información actualizada, con la finalidad de identificar y satisfacer las necesidades más indispensables. Esto serviría para emplear los recursos lo mejor posible y comparar el progreso observado a partir de las evaluaciones previas.

Otra línea de investigación permitiría identificar cómo o de qué manera elevar el nivel de desarrollo de aquellas habilidades y destrezas en las que salieron bajos los egresados. De esta manera se lograrían cumplir todos los objetivos planteados en el currículo de la INCO.

Finalmente, sería pertinente otro estudio que permita identificar el nivel de desarrollo de las competencias duras y didácticas de los docentes de la INCO. De este modo, las autoridades sabrían enfocar sus esfuerzos para ayudar al desarrollo de dichas competencias. 


\section{Referencias}

Álvarez, C. (2012). Los principios de procedimiento en el diseño curricular: clave de mejora de las relaciones teoría-práctica en educación. Revista Iberoamericana sobre Calidad, Eficacia y Cambio en Educación, 10(4), 21-36. Recuperado de http://www.rinace.net/reice/numeros/arts/vol10num4/art2.pdf

Arias, F. (2012). El proyecto de investigación. Introducción a la metodología científica (6. ${ }^{\mathrm{a}} \mathrm{ed}$.). Caracas, Venezuela: Episteme.

Bautista, M. E. (2009). Manual de metodología de la investigación (3. ${ }^{a}$ ed.). Caracas, Venezuela: Talitip.

Blanco, L. A. (1996). La evaluación educativa, más proceso que producto. Madrid, España: Universitat de Lleida.

Braslavsky, C. (2006). Diez factores para una educación de calidad para todos en el siglo XXI. REICE: Revista Electrónica Iberoamericana sobre Calidad, Eficacia y Cambio en Educación, 4(2), 84-101.

Centro Universitario de la Costa (2014). Plan de desarrollo de Centro: Visión 2030. Puerto Vallarta, México: UDG. Recuperado de http://www.cuc.udg.mx/sites/default/files/Plan\%20de\%20desarrollo\%202030.pdf

Centro Universitario de la Costa (2018a). Historia. Recuperado de http://www.cuc.udg.mx/historia

Centro Universitario de la Costa (2018b). Oferta académica. Recuperado de http://www.cuc.udg.mx/oferta-academica

Consejo Nacional de Acreditación en Informática y Computación (2018). Presentación. Recuperado de http://www.conaic.net/

Consejo para la Acreditación de la Educación Superior [Copaes] (2018). ¿Qué es COPAES? Recuperado de http://www.copaes.org/

Creswell, J. W. (2012). Educational research. Planning, conducting and evaluating quantitative and qualitative research ( $4^{\text {th }}$ ed.). Boston, MA: Pearson.

Del Cid, A., Méndez, R. y Franco, S. (2011). Investigación: fundamentos y metodología (2. ${ }^{a}$ ed.). México: Pearson.

Fernández, F. (2002). El análisis de contenido como ayuda metodológica para la investigación. Revista de Ciencias Sociales, (96), 35-53.

Flick, U. (2004). Introducción a la investigación cualitativa. Madrid, España: Morata. 


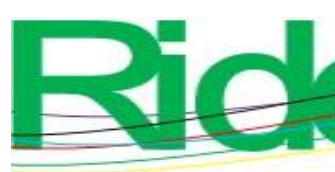

Revista Iberoamericana para la Investigación y el Desarrollo Educativo ISSN $2007-7467$

Gómez, J. y Mora, M. (2011). Los modelos de evaluación aplicados a los programas educativos de educación superior: una perspectiva bibliotecológica. Investigación Bibliotecológica, 25(53), 13-29.

Hansen, H. F. (2005). Choosing evaluation models. A discussion on evaluation design. Evaluation, 11(4), 447-462.

Hernández, R., Fernández, C. y Baptista, P. (2014). Metodología de la investigación (6. ${ }^{\text {e ed.). }}$ México: McGraw Hill.

López, F. (2002). El análisis de contenido como método de investigación. XXI. Revista de Educación, (4), 167-179.

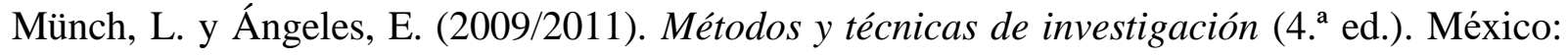
Trillas.

Stenhouse, L. (1984/2010). Investigación y desarrollo del curriculum (5. a ed.). Madrid: Morata.

Stufflebeam, D. L. y Shinkfield, A. J. (1987/2011). Evaluación sistemática: guía teórica y práctica (Trad. C. Losilla). Barcelona, España: Paidós/M.E.C.

Universidad de Guadalajara (2014). Plan de desarrollo institucional 2014-2030. Guadalajara, México: UDG. Recuperado de http://www.udg.mx/sites/default/files/adjuntos/pdi-udg2014-2030_v4.pdf

Universidad de Guadalajara (2018a). Historia. Recuperado de http://www.udg.mx/es/historia

Universidad de Guadalajara (2018b). Presentación. Recuperado de http://www.udg.mx/nuestra

Universidad de Guadalajara (2018c). Numeralia. Recuperado de http://www.udg.mx/es/reduniversitaria

Valenzuela, G. A. y Juárez, N. (2011). Diseño y validez de indicadores para evaluar el plan de estudios. Ponencia presentada en el XI Congreso Nacional de Investigación Educativa, México

D. F. Recuperado de http://www.comie.org.mx/congreso/memoriaelectronica/v11/docs/area_02/1152.pdf 


\begin{tabular}{|l|l|}
\hline Rol de Contribución & Autor (es) \\
\hline Conceptualización & Claudia Patricia Figueroa Ypiña \\
\hline Metodología & María del Consuelo Cortés Velázquez \\
\hline Software & Aurelio Enrique López Barrón \\
\hline Validación & María del Consuelo Cortés Velázquez \\
\hline Análisis Formal & Oscar Solis Rodríguez \\
\hline Investigación & Oscar Solis Rodríguez \\
\hline Recursos & Aurelio Enrique López Barrón \\
\hline Curación de datos & Aurelio Enrique López Barrón \\
\hline Escritura - Preparación del & Oscar Solis Rodríguez \\
\hline borrador original & \\
\hline Escritura - Revisión y edición & Oscar Solis Rodríguez \\
\hline Visualización & Oscar Solis Rodríguez \\
\hline Adquervisión & Claudia Patricia Figueroa Ypiña \\
\hline & \\
\hline
\end{tabular}

